Article

\title{
Temporal and Spatial Characteristics of EVI and Its Response to Climatic Factors in Recent 16 years Based on Grey Relational Analysis in Inner Mongolia Autonomous Region, China
}

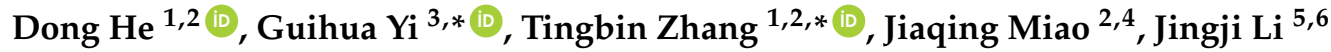 \\ and Xiaojuan Bie ${ }^{1}$ \\ 1 College of Earth Science, Chengdu University of Technology, Chengdu 610059, China; \\ 17828068016@163.com (D.H.); biexiaojuan06@cdut.cn (X.B.) \\ 2 The Engineering \& Technical College of Chengdu University of Technology, Leshan 614000, China; \\ jmiao@mtech.edu \\ 3 College of Management Science, Chengdu University of Technology, Chengdu 610059, China \\ 4 Department of Geophysical Engineering, Montana Tech of the University of Montana, Butte, MT 59801, USA \\ 5 Chengdu University of Technology, College of Environmental and Civil Engineering Institute, \\ Chengdu 610059, China; jijingli.ok@163.com \\ 6 Chengdu University of Technology, Institute of Ecological Resource and Landscape, Chengdu 610059, China \\ * Correspondence: yigh@cdut.edu.cn (G.Y.); zhangtb@cdut.edu.cn (T.Z.); \\ Tel.: +86-135-4115-2909 (G.Y.); +86-138-0821-0269 (T.Z.)
}

Received: 16 May 2018; Accepted: 13 June 2018; Published: 15 June 2018

\begin{abstract}
The Inner Mongolia Autonomous Region (IMAR) is a major source of rivers, catchment areas, and ecological barriers in the northeast of China, related to the nation's ecological security and improvement of the ecological environment. Therefore, studying the response of vegetation to climate change has become an important part of current global change research. Since existing studies lack detailed descriptions of the response of vegetation to different climatic factors using the method of grey correlation analysis based on pixel, the temporal and spatial patterns and trends of enhanced vegetation index (EVI) are analyzed in the growing season in IMAR from 2000 to 2015 based on moderate resolution imaging spectroradiometer (MODIS) EVI data. Combined with the data of air temperature, relative humidity, and precipitation in the study area, the grey relational analysis (GRA) method is used to study the time lag of EVI to climate change, and the study area is finally zoned into different parts according to the driving climatic factors for EVI on the basis of lag analysis. The driving zones quantitatively show the characteristics of temporal and spatial differences in response to different climatic factors for EVI. The results show that: (1) The value of EVI generally features in spatial distribution, increasing from the west to the east and the south to the north. The rate of change is $0.22 / 10^{\circ} \mathrm{E}$ from the west to the east, $0.28 / 10^{\circ} \mathrm{N}$ from the south to the north; (2) During 2000-2015, the EVI in IMAR showed a slightly upward trend with a growth rate of $0.021 / 10 \mathrm{a}$. Among them, the areas with slight and significant improvement accounted for $21.1 \%$ and $7.5 \%$ of the total area respectively, ones with slight and significant degradation being $24.6 \%$ and $4.3 \%$; (3) The time lag analysis of climatic factors for EVI indicates that vegetation growth in the study area lags behind air temperature by 1-2 months, relative humidity by 1-2 months, and precipitation by one month respectively; (4) During the growing season, the EVI of precipitation driving zone $(21.8 \%)$ in IMAR is much larger than that in the air temperature driving zone ( $8 \%)$ and the relative humidity driving zone (11.6\%). The growth of vegetation in IMAR generally has the closest relationship with precipitation. The growth of vegetation does not depend on the change of a single climatic factor. Instead, it is the result of the combined action of multiple climatic factors and human activities.
\end{abstract}


Keywords: EVI; climatic factor; driving force; grey relational analysis (GRA); Inner Mongolia Autonomous Region (IMAR)

\section{Introduction}

Vegetation is a key component of ecosystems, and any change in terrestrial ecosystems is bound to result in fluctuations in vegetation types, quantity, or quality [1-3]. As a comprehensive indicator, vegetation reflects the changes of the ecological environment, and studying its response to climate change has become one of the main contents of the current global change research [4-6]. The enhanced vegetation index (EVI) is an important quantitative index, reflecting the growth status of the surface vegetation and is also one of the most important basic data in ecosystems research. The change of EVI plays an important role in indicating the changes of regional ecosystems and environment [7-9]. The Inner Mongolia Autonomous Region (IMAR) is located in the transitional zone from arid and semi-arid climates to humid and semi-humid monsoon climates of the southeast coast [10-12]. It is a water conservation area of Songhua River and functions as an important ecological barrier of northern China $[11,12]$. The ecological environment in IMAR is characterized by distinctive geographical differences, fragile ecological conditions, and complex ecological types [12-14], where vegetation types show a northeast-southwest pattern of surface cover of forests, steppes and deserts [12,15]. Quantitative assessment of the dynamic changes and driving forces of the vegetation ecosystem in Inner Mongolia will help people to understand the feedback between the global climate change and vegetation ecosystems [12,14-16], which is of great theoretical and practical significance for evaluating the environmental quality of terrestrial ecosystems and regulating ecological processes $[1,16,17]$.

A lot of work has been done in studying the relationship between terrestrial vegetation and climatic factors. Related studies have found that vegetation changes in the Sahel [18], the tropical Africa [19], the Central Plains of the United States [20], and the Eurasian continent [21] are closely related to the amount of precipitation, while air temperature is the main factor that influences the growth of terrestrial vegetation in the northern Finno-Candea [22], the Arctic [23], and North America [24]. China is located in the monsoon region of eastern Asia, with complex climate types and rich vegetation types. There are also distinct differences in the correlation between vegetation changes and hydrothermal factors in different regions [25-27], as well as the time lag of response to climatic factors $[13,28,29]$.

Most of the previous studies on the relationship between vegetation remote sensing quantitative factors and climate change have been made using the method of correlation analysis [11,13,19], but the correlation analysis method usually requires that each variable should follow the joint normal distribution; thus, the extreme values of the factors in the analysis process would have a great impact on the results of correlation analysis [30-33]. Some scholars use the grey relational analysis (GRA) to study the relationship between vegetation index and climatic factors [30,32,34], but related studies are mostly conducted on the overall statistical value or limited sample sites of the study area. The results of those studies lack detailed descriptions of how different vegetation types and vegetation growing in different geomorphological characteristics of the study area respond to different climatic factors. In order to quantitatively display and evaluate the temporal and spatial features of the response of EVI to different climatic factors, the relationship between EVI and climatic factors are discussed using GRA method on the basis of time lag analysis.

\section{Materials and Methods}

\subsection{Study Area}

IMAR is located in the northern part of China (Figure 1a), stretching over the northwestern, northern, and northeastern parts of China, a narrow band from the west to the east. The total area of 
IMAR is 1.183 million square kilometers, accounting for $12.3 \%$ of the country's total area. With rich resource reserves, it is known as "Forests in the East, Mines in the West, Agriculture in the South and Animal Husbandry in the North" and it ranks first in terms of the steppe, forest, and per capita arable land in the country, also the largest prairie pastoral area in the country $[10,35,36]$. The average elevation of the study area is about $1000 \mathrm{~m}$. The climate of IMAR belongs to the transitional zone of arid and semi-arid monsoon climates to humid and semi-humid climates. The hydrothermal conditions show a northeast-southwest zonal distribution [11,12]. Due to differences in natural factors, such as hydrothermal conditions and landforms, the vegetation in IMAR has obvious east-west zonal distribution features (Figure 1b). The types of vegetation cover from the east to the west are mainly coniferous forests, broadleaf forests, steppes, desert steppes, deserts, and so on.

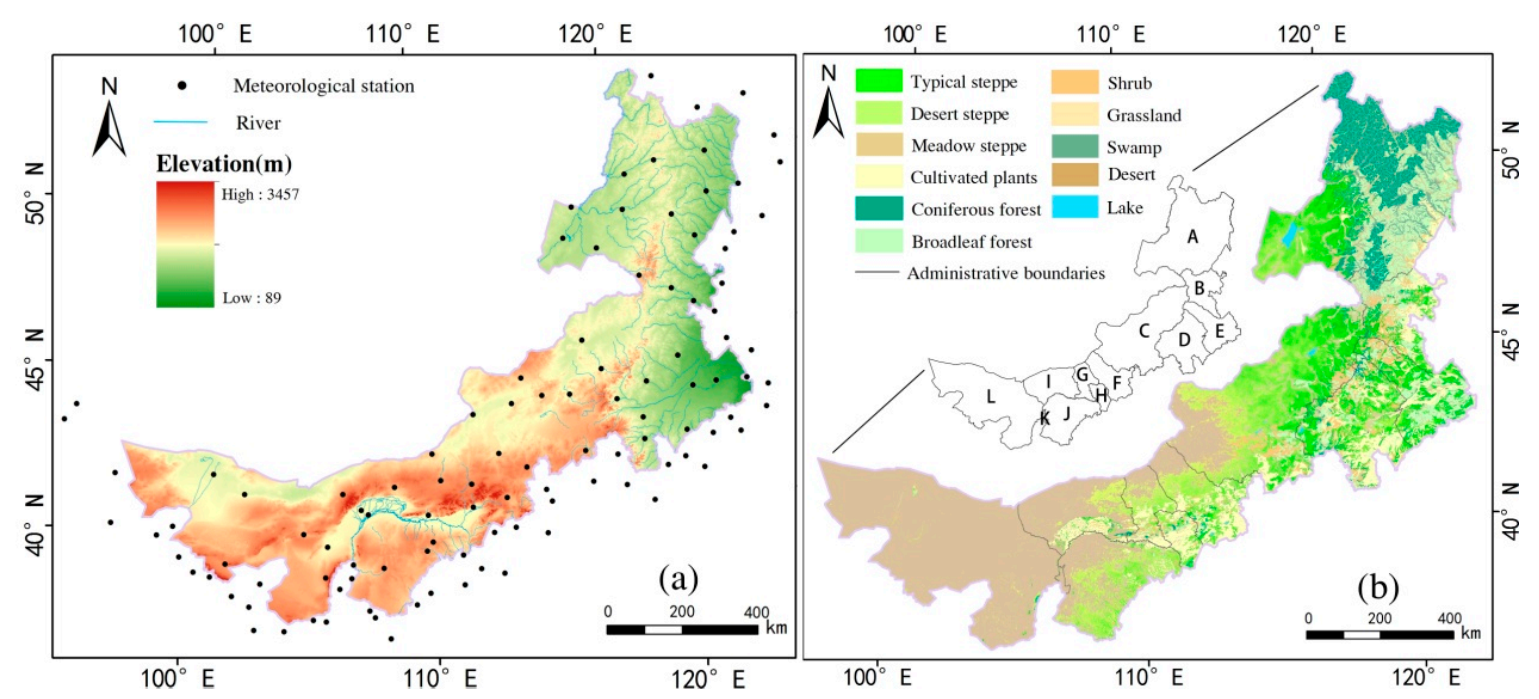

Figure 1. The Digital Elevation Model (DEM) and meteorological station distribution (a) and the vegetation types (b) in IMAR. (A-Hulunbuir; B-Hinggan League; C—Xilingol League; D—Chifeng; E-Tongliao; F-Ulanqab League; G-Baotou; H-Hohhot; I-Bayannur League; J-Erdos; K-Wuhai; L-Alxa League).

\subsection{Data Sources}

The EVI data came from the MODIS C6 MOD13Q1 dataset published by the National Aeronautics and Space Administration (NASA) of the United States. Compared with C5 data, C6 data further solves the problem of data attenuation and distortion due to the aging of satellite sensors, resulting in a significant increase in data quality. IMAR involves seven scenes of h27v04, h26v05, h26v04, h26v03, $\mathrm{h} 25 \mathrm{v} 05, \mathrm{~h} 25 \mathrm{v} 04$, and h25v03 with a spatial resolution of $250 \mathrm{~m}$ and a time resolution of $16 \mathrm{~d}$.

The meteorological data were selected from the monthly mean air temperature, monthly mean relative humidity, and monthly cumulative precipitation data from 110 meteorological stations in IMAR and its neighboring areas from February to September during year 2000-2015. The data were provided by China Meteorological Science Data Sharing Service Website (http:/ / data.cma.gov.cn).

The vegetation type data were taken from the 1:1,000,000 national vegetation type dataset published by the Data Center of Chinese Academy of Resources and Environmental Sciences (http:/ / www.resdc.cn).

Digital Elevation Model (DEM) data were taken from Advanced Spaceborne Theemal Emission and Reflection Radiometer (ASTER) global digital elevation model (ASTER GDEM) V2 digital elevation data from geospatial data cloud platform (http:/ / www.gscloud.cn) with a spatial resolution of $30 \mathrm{~m}$. 


\subsection{Data Processing}

\subsubsection{EVI Data Processing}

EVI data was affected by factors such as aerosol, ice and snow, solar illumination angle, and sensor observation angle in the process of collection and processing. There may be anomalous or missing data, which caused the seasonal trend of EVI curve to be insignificant. Therefore, in order to make EVI time series data reflect seasonal variation of vegetation correctly, it was necessary to conduct a filtering process $[9,37,38]$. Firstly, the invalid pixels in the quality control file attached to MODIS13Q1 with a value of 65,535 were removed. With full consideration of the growth periodicity of vegetation, the 16d EVI data of IMAR were smoothed using harmonic analysis of time series (HANTS) (Figure 2). During processing, the valid range was $-3000 \sim 10,000$, the period was 23, and the frequency was $2(11,23)$. The time series data after reconstruction can reflect the periodic variation of the EVI curve [9,38]. Then, using the MODIS reprojection tools (MRT), the MOD13Q1 data were pre-georeferenced to the UTM zone 48 North projection WGS-84 datum resampled with the resolution of $500 \mathrm{~m}$. Next, the monthly EVI data for vegetation in the growing season (May-September) were calculated using the method of maximum value composite (MVC). Subsequently, the effects of bare soil and sparsely vegetated areas were eliminated according to the following rules: (1) The annual mean value of EVI in the growing season was greater than 0.07 ; (2) The annual maximum value of EVI was greater than 0.10; (3) The annual maximum value of EVI should appear in July-September. Finally, the EVI pixels from May to September of the year 2000-2015, which met the requirements above, were used as the mean annual value of EVI in the growing season.
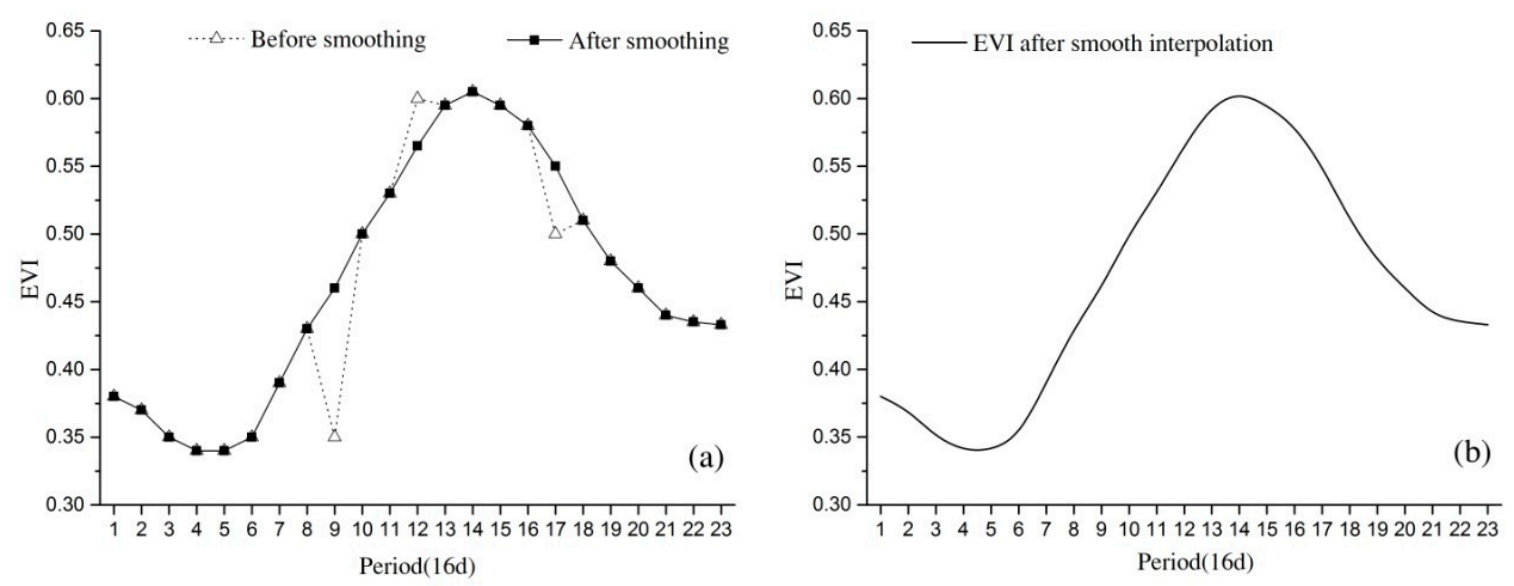

Figure 2. The EVI time series data before (a) and after (b) HANTS processing.

\subsubsection{Spatial Interpolation of Meteorological Data}

Changes in meteorological sites, observation instruments and observation methods, or environmental changes in the surroundings will lead to non-uniformity of collected data. It was necessary to conduct homogeneity tests on the data of meteorological sites [39] to eliminate invalid site data. The existing research on meteorological factor interpolation adopts different methods-Kriging and IDW (Inverse Distance Weighted) [11,40] for relative humidity, Kriging and IDW [11,32] for precipitation., and TPS (Thin Plate Spline) and Kriging [40,41] for air temperature. Considering that the spatial distribution was significantly different in relative humidity, precipitation, and air temperature, and air temperature had a certain degree of altitude sensitivity [40-42], on the basis of the previous study method, after being tested by comparing meteorological site data and other methods, IDW was selected to interpolate the relative humidity, and Kriging to interpolate the precipitation. TPS was selected and DEM acted as the covariate to assist spatial interpolation of air temperature data. The spatial resolutions of meteorological element interpolation were unified to $500 \mathrm{~m}$. 


\subsection{Methods}

\subsubsection{Trend Analytical Method}

The linear trend analysis of EVI in the growing season from 2000 to 2015 was carried out with the trend analytical method. The formula is as follows:

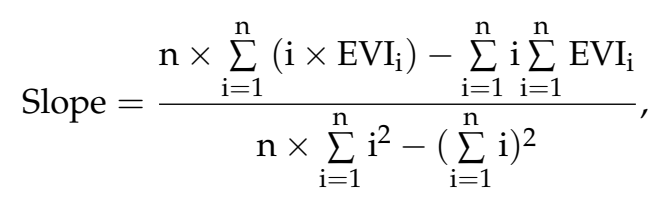

where $n$ stands for the time series (2000-2015), i.e., $n=16$; $E_{i}$ the mean EVI of the year $i$; Slope the inter-annual change slope of certain EVI pixel. When the value of Slope is positive, it indicates that EVI shows a trend of increase as time goes by, and vice versa. The formula is highly reliable and has been widely used $[11,43,44]$.

\subsubsection{Grey Relational Analysis}

Grey relation refers to the uncertain correlation between things and system factors, or factors and the main behavior. GRA is based on the geometrical approximation of the sequence of behavioral factors and the main behavioral sequence, and it is used to analyze and determine the degree of influence between factors or the contribution measure of factors to the main behavior $[45,46]$. Not restricted by the type of samples and the distribution of probability distribution, GRA is a new method to study uncertain issues with limited data and information [30].

The reference factor sequence can be expressed as:

$$
\mathrm{X}_{0}=\left[\mathrm{X}_{0}(1), \mathrm{X}_{0}(2), \ldots, \mathrm{X}_{0}(\mathrm{n})\right]
$$

The comparative factor sequence can be expressed as:

$$
X_{i}=\left[X_{i}(1), X_{i}(2), \ldots, X_{i}(n)\right], i=1,2, \ldots, m .
$$

Considering the relevant factor sequence, the point relational coefficient is defined:

$$
\mathrm{r}\left(\mathrm{x}_{0}(\mathrm{k}), \mathrm{x}_{\mathrm{i}}(\mathrm{k})\right)=\frac{\mathrm{x}(\min )+\xi \mathrm{x}(\max )}{\Delta_{0 \mathrm{i}}(\mathrm{k})+\xi \mathrm{x}(\max )}
$$

And

$$
\begin{aligned}
\Delta_{0 \mathrm{i}}(\mathrm{k}) & =\left|\mathrm{x}_{0}(\mathrm{k})-\mathrm{x}_{\mathrm{i}}(\mathrm{k})\right|, \\
\mathrm{x}(\min ) & =\min _{\mathrm{i}} \min _{\mathrm{k}} \Delta_{0 \mathrm{i}}(\mathrm{k}), \\
\mathrm{x}(\max ) & =\max _{\mathrm{i}} \max _{\mathrm{k}} \Delta_{0 \mathrm{i}}(\mathrm{k}),
\end{aligned}
$$

the Grey Relational Grade (GRG) of $\gamma\left(X_{0}, X_{i}\right)$ between $X_{i}(i=1,2, \cdots, m)$ and $X_{0}$ :

$$
\gamma\left(X_{0}, X_{i}\right)=\frac{1}{n} \sum_{k=1}^{n} r\left(x_{0}(k), x_{i}(k)\right),
$$

where $\gamma\left(x_{0}(k), x_{i}(k)\right)$ is the relational coefficient between $x_{i}$ and $x_{0}$ when it meets the condition of comparative factor $\mathrm{k}$ and the grey resolution coefficient $\xi$. The GRG is a measure of the influence of the comparative factor sequence on the reference factor sequence. When the value is closer to 1 , the effect of the comparative factor sequence on the reference factor sequence becomes more significant. 
The value of the GRG can be used as an indicator that reflects the influence of comparative factor sequence on reference factor sequence [47,48].

In this study, EVI in the growing season of 2000-2015 was used as the reference factor sequence $\left(\mathrm{X}_{0}\right)$, and the comparative factor sequence $\left(\mathrm{X}_{\mathrm{i}}\right)$ was made up of three climatic factors of air temperature, relative humidity, and precipitation during 2000-2015.

\subsubsection{Time Lag Analysis}

The EVI sequence (May-September) and the monthly mean air temperature in the growing season of the study area from 2000 to 2015 were used as two sets of variables to calculate GRG between EVI sequence and the monthly mean air temperature. Similarly, the GRG between EVI sequence in the growing season and the monthly mean air temperature (April-August, March-July and February-June) could be calculated, and that between the monthly mean relative humidity and the monthly cumulative precipitation (May-September, April-August, and March-July, February-June) could also be calculated respectively. By comparing the GRG between EVI in the growing season and different comparative factor sequence, the authors further discuss the time lag effect of EVI for climatic factors.

\section{Results}

\subsection{Inter-Annual Change of EVI in the Growing Season and Spatial Distribution Pattern}

\subsubsection{Inter-Annual Change of EVI in the Growing Season}

According to the mean EVI in the growing season of IMAR from 2000 to 2015, the inter-annual change of EVI during the study period was obtained (Figure 3). In general, the mean value of EVI in IMAR showed a rising trend with a growth rate of $0.021 / 10 \mathrm{a}$ and a multi-year mean value of 0.274 . Among them, the mean values of EVI in 2000, 2001, 2003-2007, and 2009-2011 were lower than that of the multi-year mean level. The mean values of EVI in 2002, 2008, and 2012-2015 were higher than the multi-year mean value. The minimum EVI (0.251) appeared in 2001, and the maximum EVI (0.301) appeared in 2012.

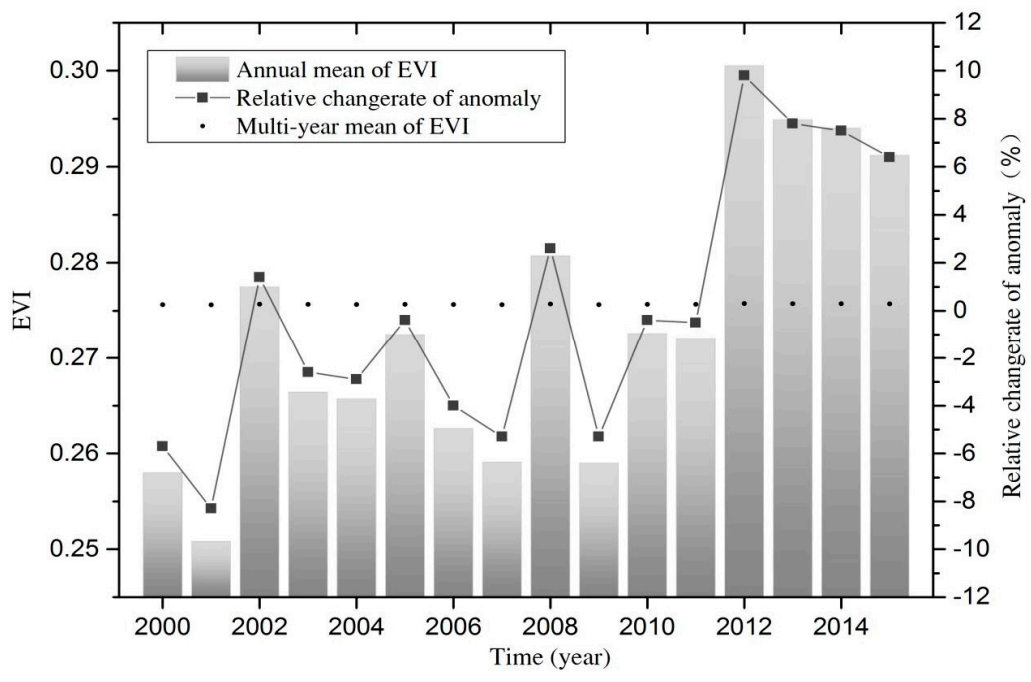

Figure 3. Inter-annual change of EVI in the study area from 2000 to 2015.

\subsubsection{Features of Spatial Distribution of Multi-Year Mean EVI}

The elevation of the study area had a characteristic of a lower height in the east and the north, and a higher height in the west and the south. The sensitivity of the vegetation to the climate gradient was strong, resulting in an uneven spatial distribution of the ecological pattern. On the whole, 
the EVI in the growth season showed a distribution pattern decreasing from the north to the south with a change rate of $0.28 / 10^{\circ} \mathrm{N}$ and from the east to the west with a rate of $0.22 / 10^{\circ} \mathrm{E}$ (Figure 4 ). The statistical results showed that areas with high EVI value in the growing season were mainly located in the areas of Hulunbuir, Hinggan League, Tongliao, and Chifeng, with an elevation below $1250 \mathrm{~m}$, between $44^{\circ}-50^{\circ} \mathrm{N}$ and $115^{\circ}-125^{\circ} \mathrm{E}$ (Figure 4 ). On the other hand, areas with low EVI value are mainly located in Xilingol League, Ulanqab League, Baotou, Bayannur League, and Erdos. The overall EVI was lower in areas where the elevation was above $2300 \mathrm{~m}$, and the vegetation types in these areas were mainly meadow steppe and desert steppe.
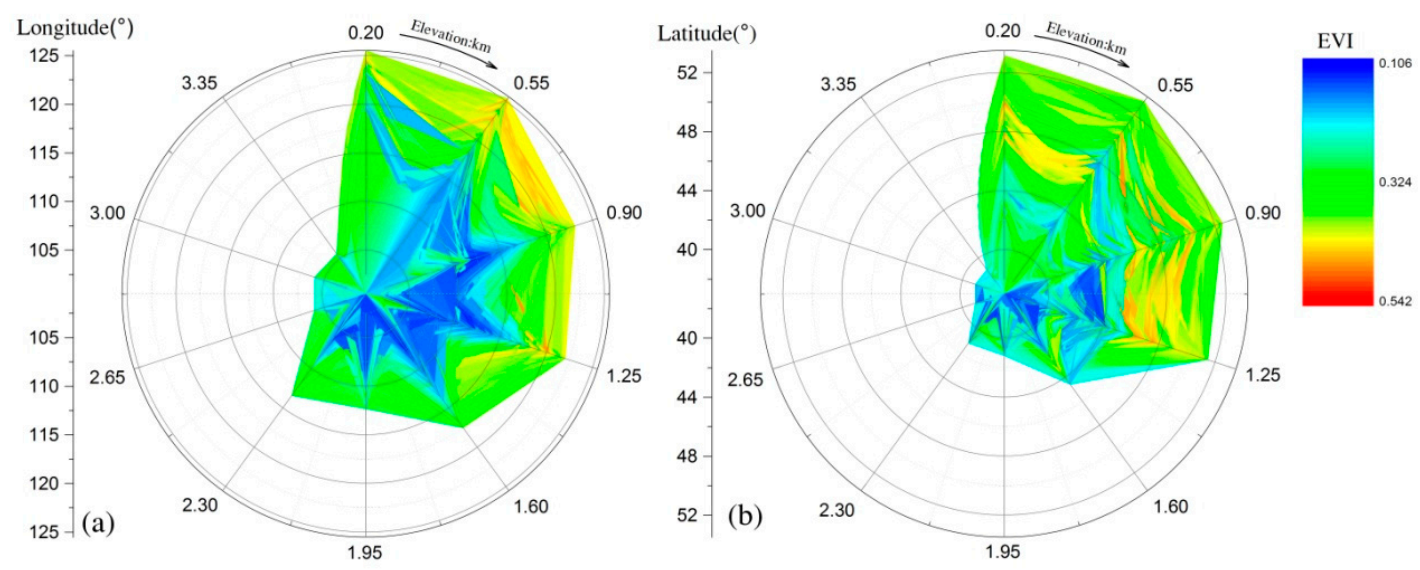

Figure 4. Spatial distribution of multi-year mean of EVI in the growing season in the study area from 2000 to 2015. (a) Longitude and altitude statistics; (b) Latitude and altitude statistics.

\subsection{Temporal and Spatial Variation of EVI in the Growing Season}

With the trend analytical method, the trend of EVI in the growing season of the study area for 16 years was drawn (Figure 5a). With the standard deviation classification method, the change trend of EVI in the study area can be divided into seven types, significant degradation, moderate degradation, slight degradation, basically unchanged, slight improvement, moderate improvement, and significant improvement (Figure 5b). On the whole, the EVI in the growing season in IMAR was basically unchanged, slightly improved, and slightly degraded. Among them, the basically unchanged areas were mainly in northern, central, and southeastern part of the study area, accounting for $42.5 \%$ of the area; and the vegetation types were mainly evergreen coniferous forests, deciduous coniferous forests, deciduous broadleaf forests, coniferous and broadleaf mixed forests, typical steppe and swamps. The areas with slight improvement were mainly in northeastern, west-central part of the study area, accounting for $21.1 \%$ of the total area; and the vegetation types were typical steppe and desert steppe. The areas where it displayed a slight degradation were mainly in the northern and southeastern part of IMAR, accounting for $24.6 \%$ of the total area; and the vegetation types were mainly typical steppe, desert steppe, deciduous coniferous forests and deciduous broadleaf forests. The areas with significant improvement mainly included Hinggan League, Hohhot, northern Xilingol League, western Hulunbuir, and southern Tongliao, accounting for 1.6\% of the total area; and the vegetation types are shrubs, meadow steppe, deciduous broadleaf forests, and mixed coniferous and broadleaf forests. The areas with moderate improvement were mainly in Chifeng, northeastern Hulunbuir, central Xilingol, and southern Erdos, accounting for 5.9\% of the total area; and the vegetation types included typical steppe, desert steppe, shrubs, and meadow grasslands. The areas with moderate degradation were mainly in Baotou, Ulanqab League, southwestern Xilingol League and eastern Hulunbuir, accounting for $3.5 \%$ of the total area; and the types of vegetation were swamps and typical steppe. The areas where there was a significant degradation were mainly located in central Hulunbuir, southeast of Xilingol League, and southeast of Ulanqab League, only accounting for $0.8 \%$, 
a small part of the total area, and the vegetation types are shrubs and typical steppe. The vegetation types that showed a trend of improvement in the study area were mainly the typical steppe in the north-central part and the desert steppe in the southern part. The vegetation types that showed a trend of degradation were mainly desert steppe in the south and coniferous and broadleaf mixed forest in the north.

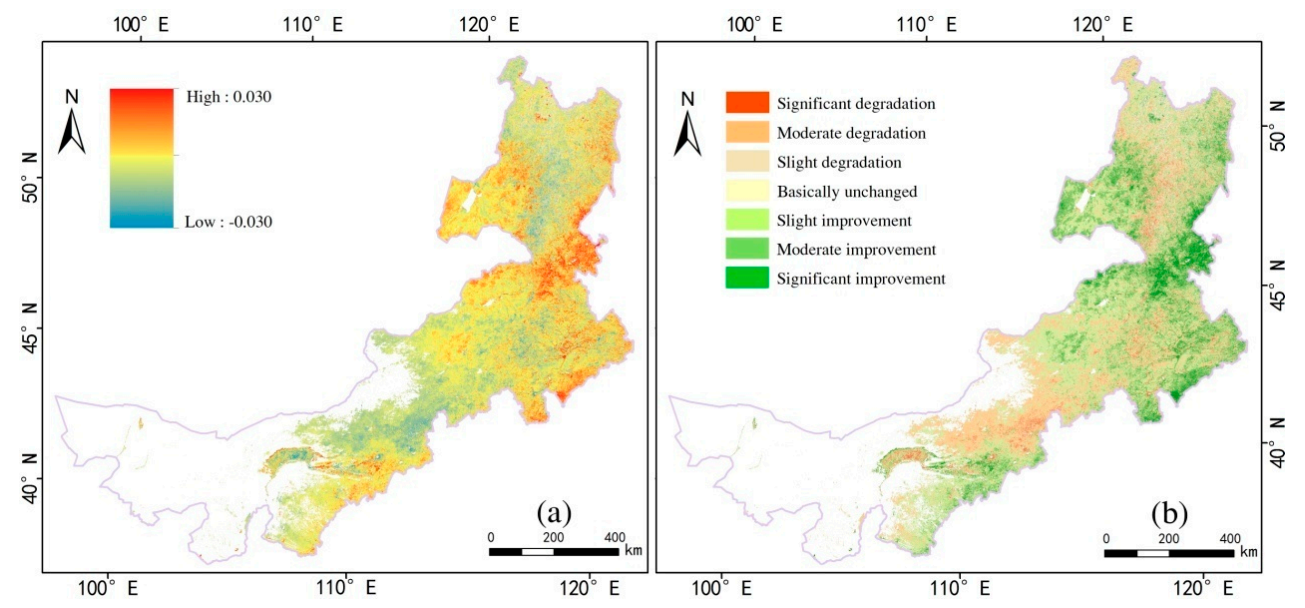

Figure 5. EVI trend (a) and EVI change (b) in the study area from 2000 to 2015.

\subsection{Time Lag Analysis of EVI in the Growing Season to Climatic Factors}

Previous studies have shown that the response of vegetation index to climatic factors show significant differences in both time and space [49,50]. And different climatic factors have different impact on vegetation with certain degree of time lag effects [32,51,52]. The GRGs are computed using the EVI in the growing season (from May to September) with different climatic factors (mean air temperature, mean relative humidity, and accumulated precipitation) in different time series (from March to July, from April to August and from May to September), resulting in the largest GRGs between EVI and climatic factors being air temperature (from April to August), relative humidity, (from March to July), and precipitation (from April to August), with GRG mean values of 0.649, 0.609, and 0.623 respectively (Figure 6). It showed that the response of growing season EVI to air temperature and relative humidity lagged by 1-2 months, and the response of growing season EVI to precipitation lagged by one month. In other words, the vegetation in the growing season of the study area responded more quickly to precipitation, and more slowly to air temperature and relative humidity.

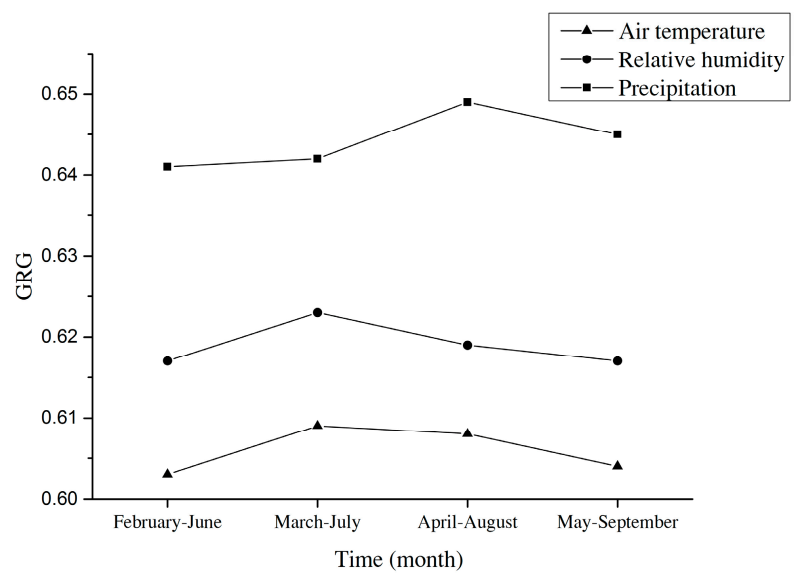

Figure 6. The GRGs of growing season EVI to air temperature, relative humidity and precipitation in February-June, March-July, April-August, and May-September. 


\subsection{GRAs between EVI and Climatic Factors}

\subsubsection{Features of Inter-Annual Change of Climatic Factors}

According to the inter-annual trends of the mean air temperature, mean relative humidity, and cumulative precipitation in the growing season of the study area from 2000 to 2015 (Figure 7), the mean air temperature reached a maximum of $11.47^{\circ} \mathrm{C}$ in 2008 , then gradually decreased, and reached its minimum of $9.69{ }^{\circ} \mathrm{C}$ in 2010 . The multi-year mean air temperature was $10.56{ }^{\circ} \mathrm{C}$ at a decline rate of $0.37^{\circ} \mathrm{C} / 10 \mathrm{a}$ and the linear trend was not obvious. The mean relative humidity reached a minimum of $46.77 \%$ in 2006 and then gradually increased, reaching a maximum of 53.8\% in 2013, and the multi-year mean relative humidity was $49.94 \%$. It generally showed an upward trend with a rate of $0.91 \% / 10 \mathrm{a}$, and the linear trend was not obvious. The minimum of cumulative precipitation $(210.69 \mathrm{~mm}$ ) occurred in 2007 after which there is a rising trend, reaching a maximum of $378.87 \mathrm{~mm}$ in 2013, and it showed a downward trend after 2013, which generally showed an upward trend. The multi-year mean cumulative precipitation was $267.43 \mathrm{~mm}$, at a growth rate of $5.833 \mathrm{~mm} / \mathrm{a}$.
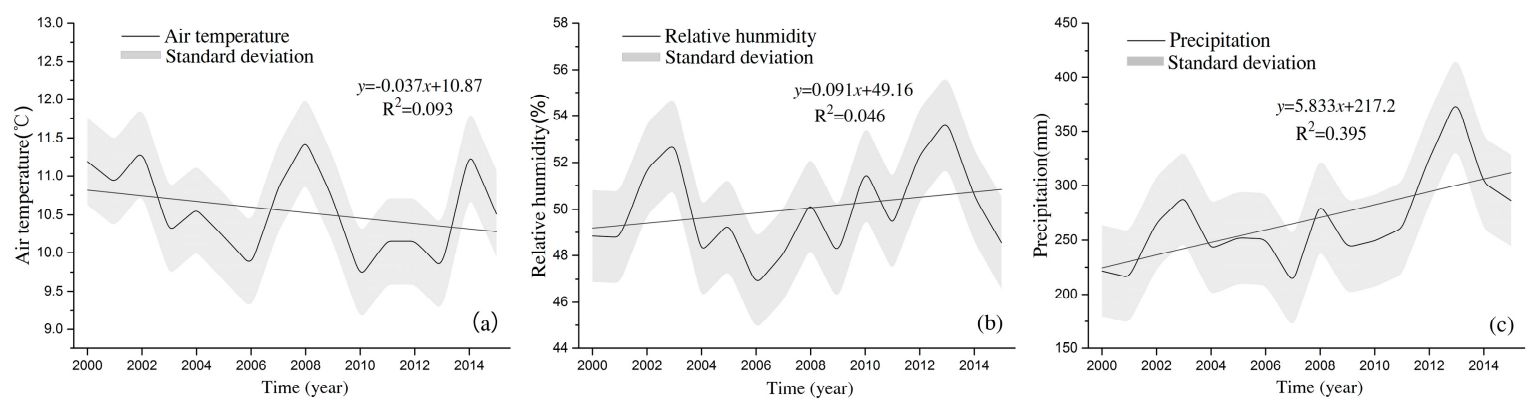

Figure 7. Inter-annual change of air temperature (a); relative humidity (b); and precipitation (c) in IMAR from 2000 to 2015 .

\subsubsection{GRAs between the Growing Season EVI and the Climatic Factors}

The GRA results of the EVI with climatic factors (Figure 8a) show that the GRG between EVI and air temperature was $0.388-0.880$ with a mean value of 0.609 . The areas with high GRG were mainly located in Hulunbuir, western Xilingol League, and eastern Bayannur League, the elevation in the areas below $2000 \mathrm{~m}$. However, the EVI value of the high GRG area was low, and the vegetation types were mainly swamps, meadow steppe, typical steppe, and desert steppe. While the low GRG areas were mainly distributed in the south-central part of Chifeng and southeastern Erdos, the elevation below $2000 \mathrm{~m}$, the EVI value of the area was high, and the vegetation types were mainly evergreen broadleaf forests, deciduous broadleaf forests, swamps, and typical steppe. It indicated that air temperature had a greater influence on the vegetation in the low-EVI areas (steppe and meadow steppe, etc.) than that of the high EVI areas (coniferous forest, broadleaf forest, etc.).

The GRA results between EVI and relative humidity in the study area (Figure 8b) display that the GRG between EVI and relative humidity was 0.385-0.902, with a mean value of 0.623 . In northern Hulunbuir and western Xilingol League with the elevation of 200-1000 m, the GRG was relatively high and the vegetation types were mainly evergreen coniferous forests, deciduous coniferous forests, deciduous broadleaf forests, coniferous and broadleaf mixed forests. In the southern Chifeng, eastern Tongliao and southern Hohhot, the elevation from 100 to $2500 \mathrm{~m}$, the GRG was relatively low and the vegetation types were mainly typical steppe, desert steppe, and shrubs. It can be seen that relative humidity had a much greater impact on forest ecological areas than on steppe ecological areas.

According to Figure $8 \mathrm{c}$, the GRA results between EVI and cumulative precipitation in the study area can be found that the GRG between EVI and cumulative precipitation was 0.398-0.893, and the mean value was 0.649. High GRG areas were mainly located in the northwestern Hulunbuir and 
southeastern Hinggan League, the elevation below $2000 \mathrm{~m}$. Evergreen coniferous forests, deciduous coniferous forests, deciduous broadleaf forests, meadow steppe and swamps were the main vegetation types in the high GRG areas. Low GRG areas were mainly distributed in the southeastern Hulunbuir, northern Hinggan League and southern Chifeng with elevation of 300-1500 m. The vegetation types of the low GRG area were mainly swamps, typical steppe, desert steppe, and coniferous and broadleaf mixed forests. The results show that although the impact of precipitation on the forest ecological areas was slightly higher than that on the steppe ecological areas, precipitation and EVI showed a high correlation in the two major areas.

According to the GRA results, there was a distinct spatial difference in the degree of vegetation response to climatic factors in the study area. In forest ecological areas, the response of vegetation to precipitation and relative humidity was generally higher than that of air temperature, the relational correlations between vegetation and precipitation and between vegetation and relative humidity showed an obvious difference. In the steppe ecological areas, the response of vegetation to precipitation and air temperature was generally higher than that of relative humidity, but the GRGs of EVI and precipitation and EVI and air temperature were very close. Figure 8 shows that at certain air temperatures, the water from precipitation directly affected the surface of the vegetation, but the water from relative humidity existed in the air. Therefore, in the typical steppe and forest areas with moderate air humidity in the northern part of the study area, precipitation had a closer relationship with vegetation growth. On the contrary in the desert steppe areas with less precipitation in the western and central parts of the study area, relative humidity played a more dominant role in vegetation growth than precipitation.

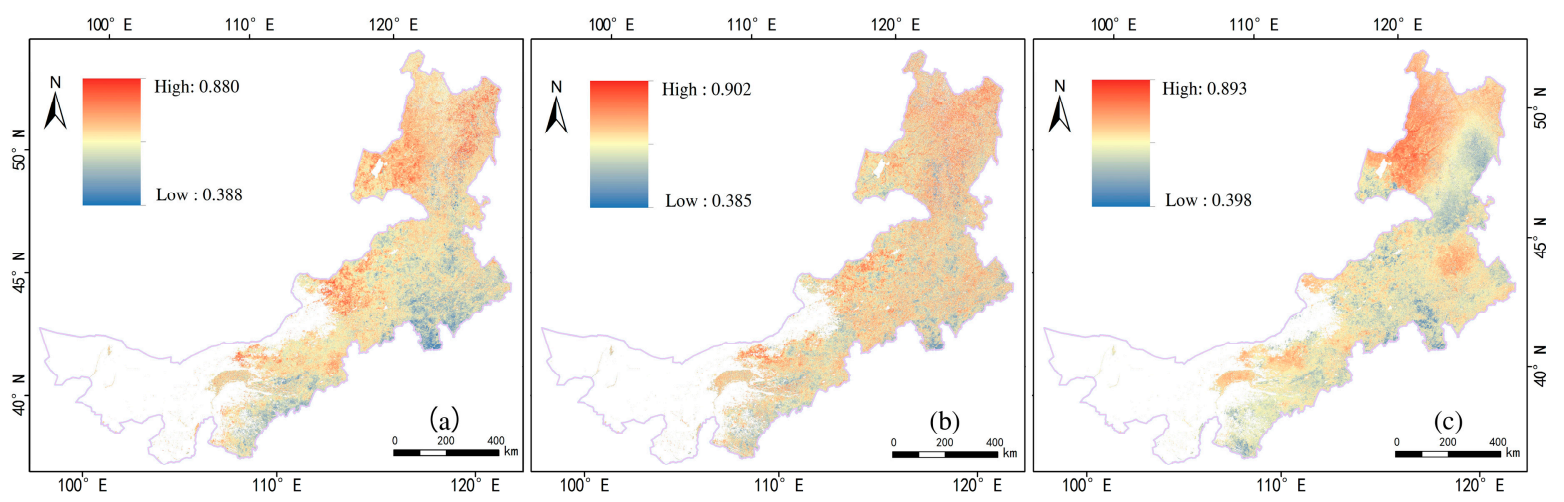

Figure 8. GRG between EVI and air temperature (a); relative humidity (b); and precipitation (c).

\subsection{Zoning of EVI for Climatic Driving Forces}

The growth of vegetation was closely related to the climate and the environment. Climate conditions, especial changes in air temperature, relative humidity, and precipitation, would have a great influence on the distribution and growth of vegetation [53]. In this paper, air temperature, relative humidity, and precipitation were chosen to zone different driving forces for EVI (Table 1).

The zoning results of driving force for EVI change in the study area (Figure 9) show that the zones where EVI change was driven by air temperature were mainly located in the north and scattered in the central and southern parts, including northeastern Hulunbuir and western Xilingol League with an elevation of $600-1400 \mathrm{~m}$. The air temperature driving zones account for $8 \%$ of the total area and the vegetation types were mainly typical steppe; and including deciduous broadleaf forests, deciduous coniferous forests, and desert steppe. The zones where relative humidity was the main driving force for EVI change were mainly distributed in the northern part of the study area, and scattered in the central and southern parts, involving Xilingol League, Chifeng, Tongliao, Baotou, and southeastern Hulunbuir, with an elevation from 200 to $1800 \mathrm{~m}$, being $11.6 \%$ of the total area. The vegetation types mainly included evergreen coniferous forests, deciduous coniferous forests, deciduous broadleaf 
forests, and coniferous and broadleaf mixed forests. In the northeastern, central and western part of IMAR, precipitation driving areas scattered in the northwest of Hulunbuir and southern part of Hinggan League and the northern part of Tongliao, where the elevation was 300-1500 m, accounting for $21.8 \%$ of the area. EVI there was driven by precipitation, and the vegetation types were mainly evergreen coniferous forests, deciduous coniferous forest and typical steppe. Others include typical steppe, swamps, and desert steppe.

Table 1. The zoning rules of driving forces for EVI change.

\begin{tabular}{|c|c|c|c|c|}
\hline \multirow{2}{*}{\multicolumn{2}{|c|}{ Driving Factors for EVI Change }} & \multicolumn{3}{|c|}{ Rules of Zoning } \\
\hline & & $\mathbf{g}_{\mathrm{T}}{ }^{1}$ & $g_{P}^{2}$ & $\mathrm{~g}_{\mathrm{R}}{ }^{3}$ \\
\hline \multirow{7}{*}{ Climatic Factors } & $\mathrm{T}^{4}$ & $\mathrm{~g}_{\mathrm{T}}>0.7$ & & \\
\hline & $\mathrm{P}^{5}$ & \multicolumn{3}{|c|}{$\mathrm{g}_{\mathrm{P}}>0.7$} \\
\hline & $\mathrm{R}^{6}$ & & & $\mathrm{~g}_{\mathrm{R}}>0.7$ \\
\hline & {$[\mathrm{T}+\mathrm{P}]^{+7}$} & $\mathrm{~g}_{\mathrm{T}}>0.7$ & $\mathrm{~g}_{\mathrm{P}}>0.7$ & \\
\hline & {$[\mathrm{T}+\mathrm{R}]^{+8}$} & $\mathrm{~g}_{\mathrm{T}}>0.7$ & & $\mathrm{~g}_{\mathrm{R}}>0.7$ \\
\hline & {$[P+R]^{+9}$} & & $\mathrm{~g}_{\mathrm{P}}>0.7$ & $\mathrm{~g}_{\mathrm{R}}>0.7$ \\
\hline & {$[\mathrm{T}+\mathrm{R}+\mathrm{P}]^{+10}$} & $\mathrm{~g}_{\mathrm{T}}>0.7$ & $\mathrm{~g}_{\mathrm{P}}>0.7$ & $\mathrm{~g}_{\mathrm{R}}>0.7$ \\
\hline
\end{tabular}

${ }^{1}$ The GRG between EVI and air temperature; ${ }^{2}$ The GRG between EVI and precipitation; ${ }^{3}$ The GRG between EVI and relative humidity; ${ }^{4}$ EVI change driven by air temperature; ${ }^{5}$ EVI change driven by precipitation; ${ }^{6}$ EVI change driven by relative humidity; ${ }^{7}$ EVI change driven by both air temperature and precipitation; ${ }^{8}$ EVI change driven by both air temperature and relative humidity; ${ }^{9} \mathrm{EVI}$ change driven by both precipitation and relative humidity; ${ }^{10} \mathrm{EVI}$ change driven by air temperature, relative humidity and precipitation.

The zones where EVI change was driven by both air temperature and precipitation were mainly distributed in the southeastern Hulunbuir with an elevation of 400-1000 m, accounting for 2.7\% of the total area. The vegetation types were mainly meadow steppe, desert steppe, and typical steppe. The zones where air temperature and relative humidity co-driving EVI change were mainly located in the eastern Hulunbuir, the elevation from 500 to $1000 \mathrm{~m}$, accounting for $3.1 \%$ of the total area. The vegetation types were mainly deciduous coniferous forests and deciduous broadleaf forests. The zones where precipitation and relative humidity co-driving EVI change were mainly located in the northern Hulunbuir, the elevation from 600 to $1100 \mathrm{~m}$, accounting for 3.8\% of the total area. The vegetation types mainly include evergreen coniferous forests, deciduous broadleaf forests. and meadow steppe. The zones where EVI change was driven by air temperature, precipitation and relative humidity were mainly distributed in the northeastern Hulunbuir, the elevation from 300 to $800 \mathrm{~m}$, accounting for $0.93 \%$ of the total area. The vegetation types were mainly evergreen coniferous forests, deciduous broadleaf forests, and typical steppe. The weak driving force of climatic factors made little contribution to the study, so the authors will not further analyze it.

The vegetation in different zones relied on water, heat, or both to different degrees. The typical steppe, coniferous forests, and cultivated plants in east-central and northwestern parts of the study area clearly showed that water was a dominant condition for vegetation growth. However, in the typical steppe area where there was a remarkable joint drive of air temperature and precipitation, it indicated that the growth of typical steppe was more dependent on the collective effect of water and heat. In the swamps, broadleaf forests, and desert steppe of the west-central part, as well as southeastern region of the northern part of the study area, air temperature and relative humidity were the main driving forces, indicating that these zones were more dependent on air temperature and humidity than on water. In the coniferous and broadleaf mixed forests of the northeastern part of the study area, where EVI was driven by air temperature, relative humidity and precipitation, it indicated that the vegetation had greater demand for air temperature, relative humidity, and precipitation. 


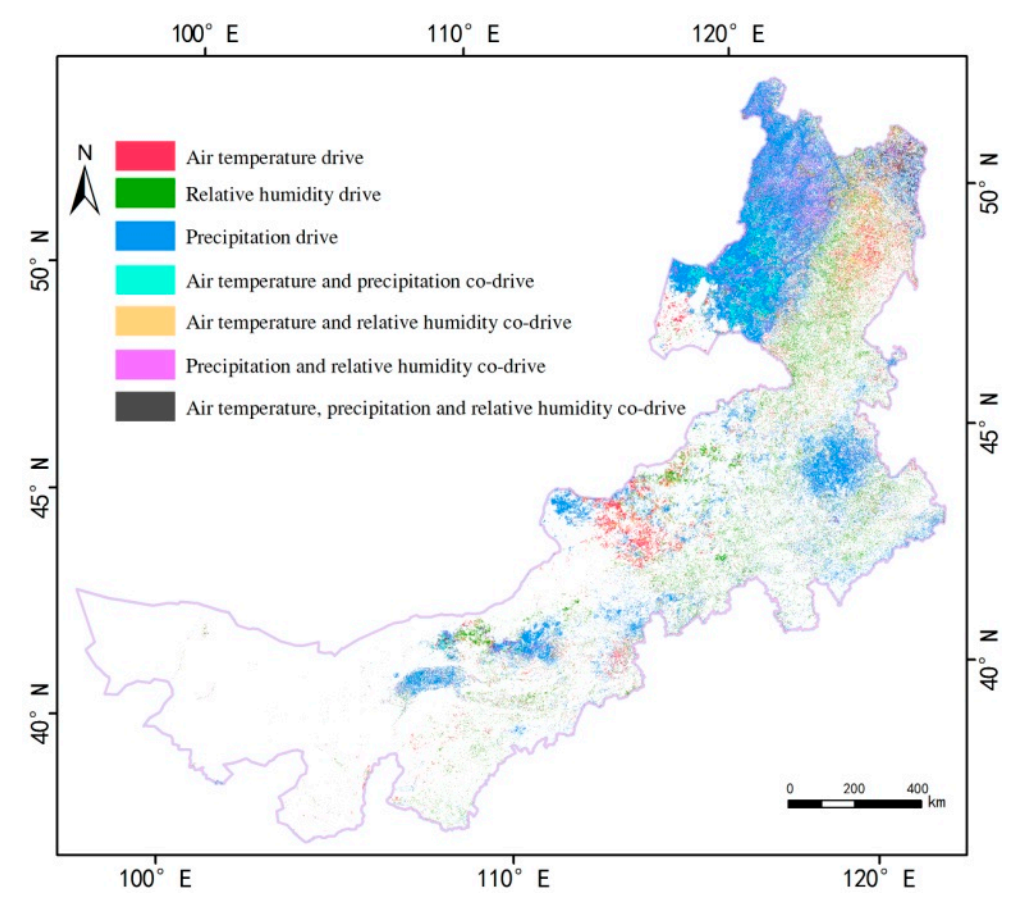

Figure 9. Areas of precipitation drive, air temperature drive, and relative humidity drive in the study area.

\section{Discussion}

Long et al. [10] used the normalized difference vegetation index (NDVI) to study the response of vegetation to climatic factors in IMAR from 1982 to 2006 and found that different vegetation types had different responses to climatic factors and different time lag, but only air temperature and precipitation were taken into consideration. Based on the MODIS data, $\mathrm{Mu}$, et al. [11] studied the response of vegetation cover to air temperature and precipitation in IMAR from 2001 to 2010. It was suggested that the relationship between vegetation cover and precipitation in IMAR was closer, and there was a certain lag in the response of vegetation growth and climatic factors but the exact time lag was not found. The NDVI data of vegetation was used to study the lagged response of precipitation in Xilingol League of IMAR from 2001 to 2007. Liu et al. [52] believed that the vegetation growth of Xilingol League in the growing season has an obvious lag to precipitation, and the time lag was about 50-60 days. Different types of steppe have different time lag. Li et al. [32] used the field sampling data and climate data from the Inner Mongolia Steppe Ecosystem Research Station of the Chinese Academy of Sciences to study the response of Carex korshinskyi to climatic factors in 2014 and found that the biomass of Carex korshinskyi lagged behind air temperature by 16 days and the relative humidity by 15 days.

The zoning of driving force in this paper shows that precipitation driving areas (21.8\%) in IMAR were much larger than the air temperature driving areas ( $8 \%$ ) and relative humidity driving areas $(11.6 \%)$, which was basically consistent with the view of Mu et al. [11]. Since this paper was based on the result of time lag analysis, the response of the forest ecological areas to precipitation and relative humidity was generally higher than that of air temperature in the spatial distribution of different zones, and the response of the steppe ecological areas to precipitation and air temperature was generally higher than that of relative humidity. Regarding the time lag of EVI in the growing season, we draw a conclusion that the time lag of EVI in IMAR to different climatic factors was about 1-2 months for air temperature, 1-2 months for relative humidity, and one month for precipitation. On one hand, data sources (especially time resolution), the selection of analysis index, and experimental errors may cause differences in results. On the other hand, the spatial resolution of remote sensing data, the size 
of interpolation grid for climatic factors, and the changes in ecological complexity may also lead to large differences in the response and time lag of the EVI to climatic factors in IMAR [11,32,52].

This paper mainly discusses the relationship between changes of IMAR vegetation EVI and climatic factors (air temperature, relative humidity, and precipitation). In addition, there was also a certain correlation between vegetation EVI and extreme weather [15]. In the desert biota of IMAR, other climate factors like wind speed also had a great impact on local biomass [54]. Changes in vegetation EVI were not only closely related to climate factors but also related to human activities and other factors $[15,55,56]$. Before the 21st century, IMAR had a declining trend in overall vegetation growth under the combined effects of climate change, social economy, and local policy changes $[57,58]$. Since the beginning of the 21st century, China has implemented a series of ecological restoration projects, such as harnessing wind and sand in the Beijing-Tianjin region, returning farmland to forests and grasslands, returning grazing land to grassland, enclosing and transferring, and IMAR is one of the key implementation areas for these projects [11,59]. At the beginning of the study period, IMAR has begun implementing state-owned afforestation, encouraging artificial afforestation, returning farmland to forests and grasslands, closing mountains for afforestation, and new closures of non-forested land and open forest land, which has resulted in effective protection and improvement of forest lands and grasslands, especially forest lands [11,26,52]. In semi-arid areas, human management of ecological zones has become a major driving force of vegetation change [54]. Similar to many studies, this study find that the vegetation in some dusty land and desert steppe (such as SonidLeft Banner and Etuoke Banner) in IMAR remained a good growing trend from 2000 to 2015, and the implementation of ecological restoration measures (such as planting tree and grass, prohibiting grazing, preventing and governing the sand) played an important role in this process [10,11,59]. According to the IMAR Statistical Yearbook [60], from 2000 to 2002, the crop area affected by natural disasters in the IMAR reduced from $48,000 \mathrm{~km}^{2}$ to $32,000 \mathrm{~km}^{2}$, the total number of grazing livestock decreased from 73.01 million to 63.27 million, the area of arable land reduced from 73,000 $\mathrm{km}^{2}$ to $69,000 \mathrm{~km}^{2}$, the area of artificial afforestation increased from $5900 \mathrm{~km}^{2}$ to $9100 \mathrm{~km}^{2}$, and the population decreased from 23.77 million to 22.79 million. The EVI index increased significantly from 0.251 in 2001 to 0.278 in 2002 under the combined effect of reduced intensity in natural disasters, grazing and human activity, in addition to greater intensity in returning farmland to forests and grasslands, and the impact of climate change. Subsequently, from 2002 to 2007, the area of artificial afforestation decreased from $9100 \mathrm{~km}^{2}$ to $5900 \mathrm{~km}^{2}$, the total population increased from 22.79 million to 24.05 million, the total number of livestock increased from 63.27 million to a maximum of 100.04 million, resulting in an increase of grazing intensity. The superposition effect resulted in a slow decline in the EVI index between 2002 and 2007, with the lowest mean value of 0.259. From 2007 to 2008, the total number of livestock decreased by $5 \%$ and the area of artificial afforestation increased to $7200 \mathrm{~km}^{2}$, with EVI reaching a peak mean value of 0.281 in 2008 . From 2008 to 2011, the total population, the crop area affected by natural disasters and the total number of livestock increased slowly, while the area of artificial afforestation remains basically unchanged, therefore, the EVI of IMAR vegetation slowly declined from 2008 to 2011. In 2012, the area of artificial afforestation increased to $7800 \mathrm{~km}^{2}$, and the crop area affected by natural disasters fell to $26,000 \mathrm{~km}^{2}$. Therefore, the EVI of IMAR increased significantly by $10.44 \%$, reaching the highest mean value of 0.301 during the study period. After 2012, the area of artificial afforestation remained basically unchanged, but the total number of livestock increased by $20 \%$. The crop area affected by natural disasters increased significantly from $26,000 \mathrm{~km}^{2}$ in 2012 to $101,000 \mathrm{~km}^{2}$ in 2015. This, together with the impact of climate change, led to a declining trend of EVI in IMAR from 2012 to 2015. In general, from 2000 to 2015, the total population increased by 6.3\%, the total number of livestock increased by $65.7 \%$, so the increase in the intensity of human activities year by year will cause the growth rate of vegetation in IMAR to slow down. Human disturbance at different time periods has different effects on vegetation growth, and such positive or negative influences will increase the inter-annualecological complexity of IMAR, and change the response 
sensitivity of vegetation EVI to climate factors. Eventually, it led to differences in the response degree and response speed of EVI to air temperature, relative humidity, and precipitation [11].

\section{Conclusions}

Based on the MOD13Q1 EVI remote sensing data, vegetation type data, topographical data, and three climatic data (air temperature, relative humidity, and precipitation) of different time series, the temporal and spatial distribution patterns and changing trends of the EVI in growing season were analyzed in IMAR from 2000 to 2015. Using the method of GRA, we studied the time lag of the EVI responding to climatic factors during the 16 years and finally zone the EVI driving areas according to the different climatic factors on the basis of time lag analysis. The main conclusions were as follows:

(1) The mean EVI value in the growing season in IMAR from 2000 to 2015 was 0.274 . The spatial distribution was significantly different. The EVI value generally showed a spatial distribution of increase from west to east and from south to north. The rate of change from west to east was $0.22 / 10^{\circ} \mathrm{E}$, and that from south to north is $0.28 / 10^{\circ} \mathrm{N}$.

(2) During 2000-2015, the overall EVI in the growing season in IMAR showed a slight increasing trend, with a growth rate of $0.021 / 10 \mathrm{a}$. The areas with slight and significant improvement during the study period accounted for $21.1 \%$ and $7.5 \%$ of the total study area. The areas with slight and significant degradation accounted for $24.6 \%$ and $4.3 \%$ of the total study area.

(3) The results of time lag analysis show that the response time of EVI in IMAR to the three climatic factors (air temperature, relative humidity and precipitation) was different. The EVI lagged behind air temperature by 1-2 months, relative humidity by $1-2$ months, and precipitation by one month.

(4) The precipitation driving areas (21.8\%) in IMAR were much larger than air temperature driving ones $(8 \%)$ and the relative humidity driving ones (11.6\%). The EVI in the study area had the closest relationship with precipitation, followed by the relative humidity, and then air temperature. However, the growth of vegetation did not depend on the change of a single climate factor, but was the result of the collective effect of multiple climatic factors and human activities.

Author Contributions: D.H., G.Y., and T.Z. jointly designed the study and wrote the thesis. J.M., J.L., and X.B. all participated in the process of discussion, editing, and revision.

Funding: This research was funded by the National Natural Science Foundation of China (41501060), the China Geological Survey (DD20160015-26) and the accented term of natural science of Sichuan Provincial Education Department (18ZA0042).

Acknowledgments: The author thanks anonymous reviewers for providing invaluable comments on the original manuscript.

Conflicts of Interest: The authors declare no conflicts of interest.

\section{References}

1. Guo, L.; Wu, S.; Zhao, D.; Yin, Y.; Leng, G.; Zhang, Q. NDVI-Based vegetation change in Inner Mongolia from 1982 to 2006 and its relationship to climate at the biome scale. Adv. Meteorol. 2014, 4, 79-92. [CrossRef]

2. Xu, G.; Zhang, H.; Chen, B.; Zhang, H.; Innes, J.; Wang, G.; Yan, J.; Zheng, Y.; Zhu, Z.; Mvneni, R. Changes in Vegetation Growth Dynamics and Relations with Climate over China's Landmass from 1982 to 2011. Remote Sens. 2014, 6, 3263-3283. [CrossRef]

3. Hantson, S.; Knorr, W.; Schurgers, G.; Pugh, T.A.M.; Arneth, A. Global isoprene and monoterpene emissions under changing climate, vegetation, $\mathrm{CO}_{2}$, and land use. Atmos. Environ. 2017, 155, 35-45. [CrossRef]

4. Xin, Z.; Xu, J.; Zheng, W. Spatiotemporal variations of vegetation cover on the Chinese Loess Plateau (1981-2006): Impacts of climate changes and human activities. Sci. China Ser. D 2008, 51, 67-78. [CrossRef]

5. Stralberg, D.; Bayne, E.M.; Cumming, S.G.; Solymos, P.; Song, S.J.; Schmiegelow, F.K.A. Conservation of future boreal forest bird communities considering lags in vegetation response to climate change: A modified refugia approach. Divers. Distrib. 2015, 21, 1112-1128. [CrossRef] 
6. Keersmaecker, W.D.; Lhermitte, S.; Hill, M.; Tits, L.; Coppin, P.; Somers, B. Assessment of regional vegetation response to climate anomalies: A case study for australia using GIMMS NDVI time series between 1982 and 2006. Remote Sens. 2017, 9, 34. [CrossRef]

7. Sarkar, S.; Kafatos, M. Interannual variability of vegetation over the Indian sub-continent and its relation to the different meteorological parameters. Remote Sens. Environ. 2004, 90, 268-280. [CrossRef]

8. Peters, A.J. A spatial regression procedure for evaluating the relationship between AVHRR-NDVI and climate in the northern Great Plains. Int. J. Remote Sens. 2004, 25, 297-311. [CrossRef]

9. Cao, R.; Chen, J.; Shen, M.; Tang, Y. An improved logistic method for detecting spring vegetation phenology in grasslands from MODIS EVI time-series data. Agric. For. Meteorol. 2015, 200, 9-20. [CrossRef]

10. Long, H.; Li, X.; Bao, Y.; Huang, L.; Li, Z. Time lag analysis between vegetation and climate change in Inner Mongolia. In Proceedings of the IEEE International Geoscience and Remote Sensing Symposium, Honolulu, HI, USA, 25-30 July 2010; pp. 1513-1516.

11. Mu, S.; Li, J.; Chen, Y.; Gang, C.; Zhou, W.; Ju, W. Spatial differences of variations of vegetation coverage in Inner Mongolia during 2001-2010. Acta Geogr. Sin. 2012, 67, 1255-1268. [CrossRef]

12. Ren, S.; Yi, S.; Peichl, M.; Wang, X. Diverse responses of vegetation phenology to climate change in different grasslands in Inner Mongolia during 2000-2016. Remote Sens. 2017, 10, 17. [CrossRef]

13. Piao, S.; Fang, J.; He, J. Variations in vegetation net primary production in the Qinghai-Xizang Plateau, China, from 1982 to 1999. Clim. Chang. 2006, 74, 253-267. [CrossRef]

14. Tong, S.; Zhang, J.; Si, H.; Lai, Q.; Ma, Q. Dynamics of Fractional Vegetation Coverage and Its Relationship with Climate and Human Activities in Inner Mongolia, China. Remote Sens. 2016, 8, 776. [CrossRef]

15. Li, C.L.; Wang, J.; Hu, R.C.; Yin, S.; Bao, Y.H.; Ayal, D.Y. Relationship between vegetation change and extreme climate indices on the Inner Mongolia Plateau, China, from 1982-2013. Ecol. Indic. 2018, 89, 101-109. [CrossRef]

16. Chen, L.Y.; Li, H.; Zhang, P.J.; Zhao, X.; Zhou, L.H.; Liu, T.Y.; Hu, H.F.; Bai, Y.F.; Shen, H.H.; Fang, J.Y. Climate and native grassland vegetation as drivers of the community structures of shrub-encroached grasslands in Inner Mongolia, China. Landsc. Ecol. 2015, 30, 1627-1641. [CrossRef]

17. Bai, Y.; Wu, J.; Xing, Q.; Pan, Q.; Huang, J.; Yang, D.; Han, X. Primary production and rain use efficiency across a precipitation gradient on the Mongolia Plateau. Ecology 2008, 89, 2140-2153. [CrossRef] [PubMed]

18. Anyamba, A.; Tucker, C.J. Analysis of Sahelian vegetation dynamics using NOAA-AVHRR NDVI data from 1981-2003. J. Arid Environ. 2005, 63, 596-614. [CrossRef]

19. Camberlin, P.; Martiny, N.; Philippon, N.; Richard, Y. Determinants of the interannual relationships between remote sensed photosynthetic activity and rainfall in tropical Africa. Remote Sens. Environ. 2007, 106, $199-216$. [CrossRef]

20. Wardlow, B.D.; Egbert, S.L. Large-area crop mapping using time-series MODIS 250m NDVI data: An assessment for the U.S. Central Great Plains. Remote Sens. Environ. 2008, 112, 1096-1116. [CrossRef]

21. Piao, S.; Wang, X.; Ciais, P.; Zhu, B.; Wang, T.; Liu, J. Changes in satellite-derived vegetation growth trend in temperate and boreal Eurasia from 1982 to 2006. Glob. Chang. Biol. 2011, 17, 3228-3239. [CrossRef]

22. Karlsen, S.R.; Tolvanen, A.; Kubin, E.; Poikolainen, J.; Hogda, K.A.; Johansen, B.; Danks, F.S.; Aspholm, P.; Wielgolaski, F.E.; Makarova, O. MODIS-NDVI-based mapping of the length of the growing season in northern Fennoscandia. Int. J. Appl. Earth Obs. 2008, 10, 253-266. [CrossRef]

23. Raynolds, M.K.; Comiso, J.C.; Waiker, D.A.; Verbyla, D. Relationship between satellite-derived land surface temperatures, arctic vegetation types, and NDVI. Remote Sens. Environ. 2008, 112, 1884-1894. [CrossRef]

24. Wang, X.; Piao, S.; Ciais, P.; Li, J.; Friedlingstein, P.; Koven, C.; Chen, A. Spring temperature change and its implication in the change of vegetation growth in North America from 1982 to 2006. Proc. Natl. Acad. Sci. USA 2011, 108, 1240-1245. [CrossRef] [PubMed]

25. Zhao, X.; Tan, K.; Zhao, S.; Fang, J. Changing climate affects vegetation growth in the arid region of the northwestern China. J. Arid Environ. 2011, 75, 946-952. [CrossRef]

26. Dan, S.; Li, H.; Ping, L.; De, X. Effects of Climate Change on Vegetation in Desert Steppe Inner Mongolia. Nat. Resour. 2013, 4, 319-322. [CrossRef]

27. Qu, H.; Wang, C.J.; Zhang, Z.X. Planning priority conservation areas under climate change for six plant species with extremely small populations in China. Nat. Conserv. 2018, 25, 89-106. [CrossRef] 
28. Hu, M.Q.; Mao, F.; Sun, H.; Hou, Y.Y. Study of normalized difference vegetation index variation and its correlation with climate factors in the three-river-source region. Int. J. Appl. Earth Obs. 2011, 13, 24-33. [CrossRef]

29. Lin, Y.; Xin, X.; Zhang, H.; Wang, X. The implications of serial correlation and time-lag effects for the impact study of climate change on vegetation dynamics-A case study with Hulunber meadow steppe, Inner Mongolia. Int. J. Remote Sens. 2015, 36, 5031-5044. [CrossRef]

30. Zhang, Y.; Zhou, W. Correlation analysis between vegetation fraction and vegetation indices in reclaimed forest: A case study in Pingshuo mining area. In Proceedings of the IEEE International Workshop on Earth Observation and Remote Sensing Applications, Guangzhou, China, 4-6 July 2016; pp. 122-126.

31. Ballantyne, M.; Treby, D.L.; Quarmby, J.; Pickering, C.M. Comparing the impacts of different types of recreational trails on grey box grassy-woodland vegetation: Lessons for conservation and management. Aust. J. Bot. 2016, 64, 246-259. [CrossRef]

32. Li, J.; Zhang, C.Q.; Zhang, J. The Lag Response of the Growth Dynamics of Dominant Grasses to Meteorological Factors in Typical Steppe of Inner Mongolia. Acta Agrestia Sin. 2017, 25, 267-272. [CrossRef]

33. Klinge, M.; Dulamsuren, C.; Erasmi, S.; Karger, D.N.; Hauck, M. Climate effects on vegetation vitality at the treeline of boreal forests of Mongolia. Biogeosciences 2018, 15, 1-25. [CrossRef]

34. Jin, X.; Xu, X. Rmote sensing of leaf water content for winter wheat using grey relational analysis (GRA), stepwise regression method (SRM) and partial least squares (PLS). In Proceedings of the IEEE First International Conference on Agro-Geoinformatics, Shanghai, China, 2-4 August 2012; pp. 1-5.

35. Liu, D.; Yue, L.; Wang, T.; Peylin, P.; Macbean, N.; Ciais, P.; Jia, G.S.; Ma, M.G.; Ma, Y.M.; Shen, M.G.; et al. Contrasting responses of grassland water and carbon exchanges to climate change between Tibetan Plateau and Inner Mongolia. Agric. For. Meteorol. 2018, 249, 163-175. [CrossRef]

36. Dong, Z.Q.; Pan, Z.H.; He, Q.J.; Wang, J.L.; Huang, L.; Pan, Y.Y.; Han, G.L.; Xue, X.P.; Chen, Y.C. Vulnerability assessment of spring wheat production to climate change in the Inner Mongolia region of China. Ecol. Indic. 2018, 85, 67-78. [CrossRef]

37. Malingreau, J.P. Global vegetation dynamics: Satellite observations over Asia. Int. J. Remote Sens. 1986, 7 , 1121-1146. [CrossRef]

38. Roerink, G.J.; Menenti, M.; Verhoef, W. Reconstructing cloudfree NDVI composites using Fourier analysis of time series. Int. J. Remote Sens. 2000, 21, 1911-1917. [CrossRef]

39. Xu, Z.X.; Wang, D.J.; Gao, J. Homogeneity Test on Temperature Series in Liaoning Province. J. Anhui Agric. Sci. 2010, 27, 15149-15151. [CrossRef]

40. Zhang, X.; Shao, J.; Luo, H. Spatial interpolation of air temperature with ANUSPLIN in Three Gorges Reservoir Area. In Proceedings of the IEEE International Conference on Remote Sensing, Environment and Transportation Engineering, Nanjing, China, 24-26 June 2011; pp. 3465-3468.

41. Yan, L.; Zhou, G.S.; Wang, Y.H.; Hu, T.Y.; Sui, X.H. The spatial and temporal dynamics of carbon budget in the alpine grasslands on the Qinghai-Tibetan Plateau using the Terrestrial Ecosystem Model. J. Clean Prod. 2015, 107, 195-201. [CrossRef]

42. Way, R.G.; Lewkowicz, A.G.; Bonnaventure, P.P. Development of moderate-resolution gridded monthly air temperature and degree-day maps for the Labrador-Ungava region of northern Canada. Int. J. Climatol. 2017, 37, 493-508. [CrossRef]

43. Xu, Y.; Yang, J.; Chen, Y. NDVI-based vegetation responses to climate change in an arid area of China. Theor. Appl. Climatol. 2016, 126, 213-222. [CrossRef]

44. Testa, S.; Soudani, K.; Boschetti, L.; Mondino, E.B. MODIS-derived EVI, NDVI and WDRVI time series to estimate phenological metrics in French deciduous forests. Int. J. Appl. Earth Obs. 2018, 64, 132-144. [CrossRef]

45. Chan, J.W.K. Product end-of-life options selection: Grey relational analysis approach. Int. J. Prod. Res. 2008, 46, 2889-2912. [CrossRef]

46. Shen, C.; Wang, Y.; Wei, Y.; Yu, L. A lag analysis of R\&D investment driving economic growth using grey relational model. In Proceedings of the IEEE International Conference on Environmental Science and Information Application Technology, Wuhan, China, 17-18 July 2010; pp. 61-64.

47. Yi, G.H.; Deng, W.; Li, A.N.; Zhang, T.B. Response of Lakes to Climate Change in Xainza Basin Tibetan Plateau Using Multi-Mission Satellite Data from 1976 to 2008. J. Mt. Sci. Engl. 2015, 12, 604-613. [CrossRef] 
48. Yi, G.H.; Zhang, T.B. Delayed Response of Lake Area Change to Climate Change in Siling Co Lake, Tibetan Plateau, from 2003 to 2013. Int. J. Environ. Res. Public Health 2015, 12, 13886-13900. [CrossRef] [PubMed]

49. Lei, J.; Peters, A.J. Assessing vegetation response to drought in the northern Great Plains using vegetation and drought indices. Remote Sens. Environ. 2003, 87, 85-98. [CrossRef]

50. Nezlin, N.P.; Kostianoy, A.G.; Li, B.L. Inter-annual variability and interaction of remote-sensed vegetation index and atmospheric precipitation in the Aral Sea region. J. Arid Environ. 2005, 62, 677-700. [CrossRef]

51. Goward, S.N.; Prince, S.D. Transient effects of climate on vegetation dynamics: Satellite observations. J. Biogeogr. 1995, 22, 549-564. [CrossRef]

52. Liu, C.L.; Fan, R.H.; Wu, J.J.; Yan, F. Temporal lag of grassland vegetation growth reponse to precipitation in xilinguolemeng. Arid Land Geogr. 2009, 32, 512-518. [CrossRef]

53. Pyankov, V.I.; Black, C.C. C4 plants in the vegetation of Mongolia: Their natural occurrence and geographical distribution in relation to climate. Oecologia 2000, 123, 15-31. [CrossRef] [PubMed]

54. Xu, L.; Tu, Z.; Zhou, Y.; Yu, G. Profiling Human-Induced Vegetation Change in the Horqin Sandy Land of China Using Time Series Datasets. Sustainability 2018, 10, 1068. [CrossRef]

55. Greene, R.S.B.; Nettleton, W.D.; Chartres, C.J.; Leys, J. Runoff and micromorphological properties of a grazed haplargid, near Cobar, NSW, Australia. Soil Res. 1998, 36, 87-108. [CrossRef]

56. Schuman, G.E.; Reeder, J.D.; Manley, J.T.; Hart, R.H.; Manley, W.A. Impact of grazing management on the carbon and nitrogen balance of a mixed-grass rangeland. Ecol Appl. 1999, 9, 65-71. [CrossRef]

57. John, R.; Chen, J.; Lu, N.; Wilske, B. Land cover/land use change in semi-arid Inner Mongolia: 1992-2004. Environ. Res. Lett. 2009, 4, 4-13. [CrossRef]

58. Yin, H. Understanding Land Use And Land Cover Change In Inner Mongolia Using Remote Sensing Time Series. Ph.D. Thesis, Humboldt-Universitat zu Berlin, Berlin, Germany, 2014.

59. Yin, H.; Pflugmacher, D.; Li, A.; Li, Z.; Hostert, P. Land use and land cover change in Inner Mongolia-understanding the effects of China's re-vegetation programs. Remote Sens. Environ. 2018, 204, 918-930. [CrossRef]

60. Bureau of stati of Inner Mongolia Autonomous Region. Available online: http://www.nmgtj.gov.cn/ (accessed on 15 June 2018). 